\title{
Pemanfaatan Batu Gunung Sopai Kabupaten Toraja Utara Dalam Campuran Laston Lapis Aus
}

\author{
Wadyansah Pabisa*1, Alpius ${ }^{\star 2}$, Charles Kamba*3 \\ ${ }^{* 1}$ Mahasiswa Program Studi Teknik Sipil, Universitas Kristen Indonesia Paulus, Makassar, Indonesia \\ wadyansahp@gmail.com \\ *2 Dosen Program Studi Teknik Sipil, Universitas Kristen Indonesia Paulus, Makassar, Indonesia \\ alpiusnini@gmail.com \\ *3 Dosen Program Studi Teknik Sipil, Universitas Kristen Indonesia Paulus, Makassar, Indonesia \\ kamba.charles@gmail.com
}

\begin{abstract}
ABSTRAK
Penelitian ini dimaksudkan untuk mendapatkan hasil uji karakteristik dari Laston Lapis Aus batu Gunung Sopai yang bertujuan mengetahui karakteristik laston lapis aus. Menurut tes laboratorium metode yang digunakan dalam penelitian ini adalah melakukan beberapa uji karakteristik yaitu agregat kasar, agegat halus, filler dengan aspal, lalu desain komposisi tersebut dan kemudian menguji Marshall dengan campuran Laston Lapis Aus dan kadar aspal yang optimal, diperoleh sisa kestabilan Marshall dari campuran tersebut. Hasil tdari penelitian material bentuk perkerasan jalan batuan Sopai di Kabupaten Toraha Utara telah memenuhi Ketentuan Umum Bina Marga Tahun 2018, sebagai lapisan dari permukaan jalan. Dari hasil penujian yang telah dilakukan untuk Laston lapis Aus dengan kadar 5.50\%, 6.00\%, 6.50\%, $7.00 \%$ dan $7.50 \%$. Hasil uji perendaman Marshall campuran Laston Lapis Aus untuk kadar aspal terbaik $7.50 \%$, sisa kestabilan Marshall adalah 99,35\% masuk dalam persyaratan yaitu minimal $90 \%$.
\end{abstract}

Kata kunci: Karakteristik, Komposisi Campuran Laston Lapis Aus.

\begin{abstract}
This research study is intended to obtain the characteristic test results of the Laston Lapis Aus Sopai mountain rock which aims to determine the characteristics of laston lapis wear. According to the laboratory test, the method used in this research is to perform several characteristic tests, namely coarse aggregate, fine aggat, filler with aspal, then design the composition and then test Marshall with a mixture of Laston Lapis Aus and optimal aspal levels, the remaining Marshall stability from the mixture is obtained. The result of the research on pavement form materials for the Sopai rock road in North Toraha Regency has fulfilled the 2018 General Bina Marga Provisions, as a layer of the road surface. From the results of the tests that have been carried out for Laston layers of Aus with levels of $5.50 \%, 6.00 \%, 6.50 \%, 7.00 \%$ and $7.50 \%$. The results of the Marshall Laston Lapis Aus immersion test for the best bitumen content of $7.50 \%$, the remaining Marshall stability is $99.35 \%$, which is included in the requirements, namely at least $90 \%$.
\end{abstract}

\section{Keywords: Characteristics, Composition of the Laston Lapis Aus mixture.}

\section{PENDAHULUAN}

Bertambah tingginya jumlah penduduk dalam setiap wilayah sangatlah memberi pengaruh pada perkembangan yang meningkat seiring dengan perkembangan zaman khususnya pada bidang transportasi. Persyaratan umum dari suatu jalan adalah dapat menyediakan lapisan permukaan kokoh bahkan menanggung kenyamanan yang tinggi hingga jangka layanan yang panjang yang membutuhkan pemeliharaan yang minimum bahkan bermacam iklim.

Aspal beton terbagi menjadi 3 yaitu Laston Lapis Aus (AC-WC), Laston Lapis Antara (AC-BC) dan Laston Lapis Pondasi [1], Salah satu perkerasan yang banyak digunakan adalah lapisan perkerasan Laston Lapis Aus. Lapisan perkerasan Laston Lapis Aus berfungsi melindungi lapisan dibawahnya antara lain campuran aspal, agregat, dan bahan pengisi (filler). dalam pembentukan lapisan perkerasan, agregat memiliki peran pokok dimana agregat merupakan komponen utama yang menyusun suatu campuran perkerasan yang menyebabkan daya dukung perkerasan jalan ditentukan sebagian besar dari karakteristik agregat dan bahan pengikat berupa aspal yang sangat dipengaruhi oleh mutu agregat untuk mengetahui kekuatan suatu agregat maka dilakukan pengujian karakteristik agregat.

Adapun panduan campuran beraspal yaitu Spesifikasi Bina Marga 2018 [2], maka proporsi campuran bahan perkerasan beraspal harus 
Paulus Civil Engineering Journal

E- Jurnal Teknik Sipil UKI-Paulus Makassar

http://ojs.ukipaulus.ac.id/index.php/pcej
Volume 3 No.2, Juni, 2021

ISSN Online 2775-4529

ISSN Print 2775-8613 direncanakan berdasarkan spesifikasinya. Sehingga jika karakteristik dan komposisi bahan perkerasan sudah sesuai dengan spesifikasinya, maka dilakukan pengujian melalui Marshall Konvensional dan Stabilitas Marshall Sisa untuk mengetahui kualitas dari campuran beraspal tersebut. Adapun Panduan Laboratorium Aspal (2018) menggunakan Panduan Praktikum untuk Jalan \& Aspal Teknik Sipil UKI-Paulus Makassar [3]. Adapun komposisi campuran agregat akan dibagi menjadi tiga fraksi yaitu fraksi agregat kasar, fraksi agregat halus dan fraksi bahan pengisi. Dimana ukuran dari fraksi didasarkan pada spesifikasi umum Bina Marga tahun 2018 divisi 6 [4]

Gunung Sopai adalah gunung yang berada di Kec. sopai Kab. Toraja utara yang mempunyai sumber material yang seperti batuan yang belum dipergunakan untuk bahan dasar campuran Laston Lapis Aus. Sumber daya alam yang tersedia sangat dianjurkan untuk menggunakan material yang ada disekitar lokasi pembangunan jalan karena penggunaan material di sekitar lokasi dinilai lebih efisien dari segi waktu maupun biaya.

Beberapa hal diatas mendasari penelitian ini akan dilakukan, hal tersebut tidak menghambat berjalannya penelitian ini dikarenakan agregat yang akan diteliti sudah diambil dari lokasi terkait.

Pada Penelitian ini untuk mengetahui sifat-sifat campuran menggunakan spesifikasi Bina Marga 2018 untuk sifat-sifat campuran beton aspal [5]. Kemudian untuk mengetahui metode pengujian agregat menggunakan spesifikasi Badan Penelitian dan Pengembangan Depatermen Pekerjaan Umum 2018 [6].

Adapun penelitian terkait tentang campuran Laston Lapis Aus ini ialah Fani A L (2019) yang meneliti tentang Pemanfaatan Agregat Sungai Wangger Kabupaten Nabire Sebagai Bahan Campuran ACWC dan AC-BC [7]. Penggunaan Agregat Sungai Batu Tiakka' Pada Campuran AC-BC [8]. Dengan Kadar serat ijuk 2\% untuk campuran AC-BC memiliki nilai perendaman 94,04\% [9]. Studi Karakteristik Campuran AC-BC Berdasarkan Limbah Kantong Plastik Sebagai Bahan Tambah [10]. Pemanfaatan Batu Gunung Posi' Padang Balla Kabupaten Mamasa Sebagai Campuran ACBC [11]

\section{METODE}

\section{Lokasi dan Waktu Pengambilan Material}

Lokasi pengambilan material terletak di Sopai, Kecamatan Sopai, Kabupaten Toraja Utara, Lokasi pengambilan material pada tabel 1 dibawah ini:

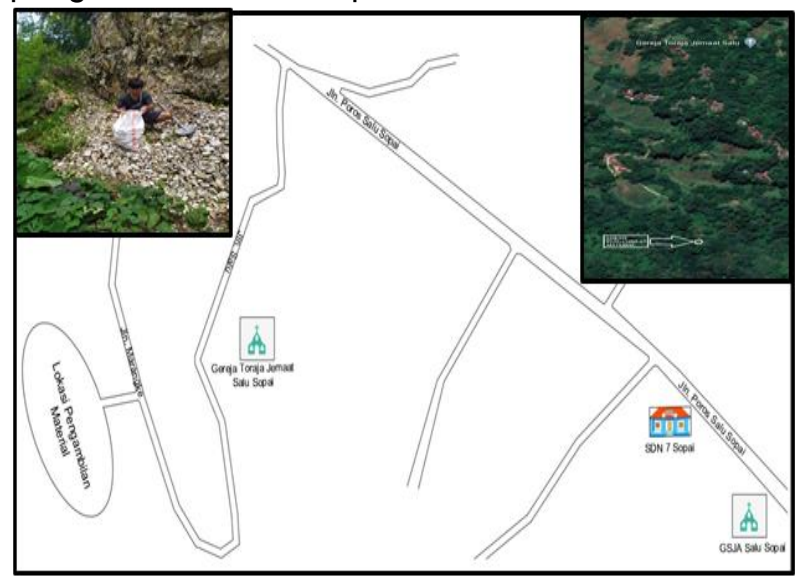

Gambar 1. Lokasi pengambilan material

\section{Pemeriksaan Karakteristik Agregat}

Beberapa pemeriksaan karakteristik agregat yang berpedoman pada standar rujukan yang dapat dilihat pada tabel berikut ini:

Tabel 1. Panduan karakteristik agregat

\begin{tabular}{cc}
\hline Karakteristik & Panduan \\
\hline Analisa Saringan & SNI ASTM C136 2012 \\
Pemeriksaan Berat Jenis dan Absorbsi Agregat Kasar & SNI $1969: 2016$ \\
Berat Jenis dan Absorbsi Agregat Halus & SNI $1970: 2016$ \\
Nilai Setara Pasir & SNI 03 4428 1997 \\
Keausan & SNI 2417 2008 \\
Partikel Pipih dan lonjong & ASTM D 4791 10
\end{tabular}




\section{Pemeriksaan Karakteristik Aspal}

Pada percobaan karakteristik aspal yang terdiri dari beberapa pengujian dan mengacu pada

Tabel 2. Panduan karakteristik aspal

\begin{tabular}{cc}
\hline Karakteristik & Panduan \\
\hline Penetrasi pada $25^{\circ} \mathrm{C}$ & SNI 2456 : 2011 \\
Titik Nyala & SNI 2433 : 2011 \\
Titik Lembek Aspal dan Ter & SNI 2434 :2011 \\
Berat Jenis & SNI 2441 : 2011 \\
Daktilitas pada $25^{\circ} \mathrm{C}$ & SNI 2432 : 2011 \\
Berat yang Hilang & SNI 06 2441 1991
\end{tabular}

\section{Evaluasi Hasil Pengujian Karakteristik Agregat, Filler dan Aspal}

Evaluasi hasil pengujian berdasarkan Standar Spesifikasi yang telah ditentukan. Spesifikasi Umum Bina Marga 2018 merupakan spesifikasi teknik pekerasan jalan dan jembatan. Sejumlah pengujian karakteristik seperti analisa saringan, pengujian kadar lumpur, pengujian lolos saringan No. 200, dan pemeriksaan partikel pipih dan lonjong dapat kembali dilakukan pemecahan standar rujukan yang dapat di lihat pada tabel 2 dibawah ini:

agregat kembali jika tidak mencapai spesifikasi agar memenuhi standar spesifikasi.

\section{Rancangan Campuran Laston Lapis Aus}

Pembagian ukuran pecahan agregat mengikuti spesifikasi umum Bina Marga divisi 6. Dimana penentuan rancangan komposisi campuran diambil dari nilai gradasi ideal agregat. Komposisi campuran agregat yang dirancang dibagi menjadi tiga bagian meliputi: bagian agregat halus, bagian agregat kasar, dan bagian filler

Tabel 3. Rancangan komposisi campuran

\begin{tabular}{|c|c|c|}
\hline \multirow{4}{*}{$\begin{array}{c}\text { Ukuran } \\
\text { Ayakan } \\
(\mathrm{mm})\end{array}$} & \multicolumn{2}{|c|}{$\%$ Berat yang Lolos terhadap Total Agregat dalam Campuran } \\
\hline & \multicolumn{2}{|c|}{ Laston } \\
\hline & Lapis Aus & \\
\hline & Spesifikasi Gradasi & $\begin{array}{c}\text { Rancangan Gradasi } \\
\text { Campuran }\end{array}$ \\
\hline $3 / 4$ & 100 & 100 \\
\hline $1 / 2$ & $90-100$ & 95,00 \\
\hline $3 / 8$ & $77-90$ & 83,50 \\
\hline 4 & $53-69$ & 61,00 \\
\hline 8 & $33-53$ & 43,00 \\
\hline 16 & $21-40$ & 30,50 \\
\hline 30 & $14-30$ & 22,00 \\
\hline 50 & $7-20$ & 15,50 \\
\hline 100 & $6-15$ & 10,50 \\
\hline 200 & 4.-9 & 6,50 \\
\hline
\end{tabular}

\section{Komposisi Campuran}

Setelah semua bahan yang akan digunakan memenuhi syarat langkah berikutnya ialah menghitung komposisi campuran serta total sampel uji.

Perhitungan Perkiraan awal kadar aspal:

Kadar aspal efektif minimal. $\quad=0,6 \%$ 
Kadar aspal efektif maksimal $=1,2 \%$

Lolos saringan Nomor $200 \quad=6,5 \%$

Kadar aspal rencana maksimum $=10,83 \%$

Kadar aspal rrencana minimum $=5,42 \%$
Komposisi campuran Kaston Lapis Aus dapat dilihat pada tabel 4 berikut ini:

Tabel 4. Komposisi campuran laston lapis aus

\begin{tabular}{|c|c|c|c|c|c|c|}
\hline \multirow{2}{*}{ Material } & \multirow{2}{*}{ Uk.Saringan } & \multicolumn{5}{|c|}{ Kadar Aspal } \\
\hline & & $5,50 \%$ & $6,00 \%$ & $6,50 \%$ & $7,00 \%$ & $7,50 \%$ \\
\hline \multirow{3}{*}{ Agregat Kasar } & $3 / 4 "$ & & & & & \\
\hline & 1/2" & 37,35 & 37,20 & 37,05 & 36.90 & 36.75 \\
\hline & 3/8" & & & & & \\
\hline \multirow{6}{*}{ Agregat Halus } & No.8 & & & & & \\
\hline & No.18 & & & & & \\
\hline & No.30 & & & & & \\
\hline & No.50 & 51,20 & 50,90 & 50.60 & 50,30 & 50,00 \\
\hline & No.100 & & & & & \\
\hline & No.200 & & & & & \\
\hline Filler & & 5,95 & 5,90 & 5,85 & 5,89 & 5,75 \\
\hline
\end{tabular}

Pada penelitian tersebut total benda uji dapat dilihat pada tabel 5 berikut ini:

Tabel 5. Jumlah benda uji

Kadar Aspal Marshall Konvensional Marshall Immersion

\begin{tabular}{lll}
\hline $5,50 \%$ & 3 & \\
$6,00 \%$ & 3 & 3 \\
$6,50 \%$ & 3 & \\
$7,00 \%$ & 3 & \\
$7,50 \%$ & 3 & \\
\hline
\end{tabular}

\section{Pengujian Marshall Konvensional}

Penelitian uji Marshall umumnya mencakup: persiapan benda uji, menentukan berat jenis bulk contoh benda uji, pemeriksaan nilai stabilitas dan flow, serta hitungan kriteria sifat volumetrik benda uji. Ada beberapa faktor yang harus diperhatikan pada persiapan benda uji antara lain:

1. Persiapan pada pengujian Marshal.

2. Menentukan temperatur campuran sertai pemadatan.

3. Memperisiapkan agregat yang hendak digunakan.

4. Kepadatan benda uji

5. Mempersiapkan campuran aspal beton.

\section{Penentuan Kadar Aspal Optimum}

Sesudah dilakukan perhitungan Marshall Konvesional yaitu nilai tertingi dari grafik hubungan vim yang didapatkan pada pengujian, kepadatan campuran yang dipadatkan dengan kadar aspal. Menurut kegunaan dan macam campuran Laston Lapis Aus sehingga ditentukan kadar aspal stabilitas tertinggi dengan flow yang paling kecil untuk Kadar Aspal optimum KAO.

\section{Pengujian Marshall Immersion}

Pengujian Marshall Immersion dilakukan untuk mengetahui ketahanan benda uji terhadap air dimana perbedaanya dengan uji marshall konvensional terletak pada lama perendaman selama 24 jam pada suhu $60^{\circ} \mathrm{C}$. Dan biasa disebut stabilitas Marshall sisa.

Hasil penelitian ini menganalogikan antara pengujian marshall setelah direndam pada suhu 
ruang $60^{\circ}$ selam 24 jam, dengan lama perendaman 30 menit (marshall konvensional) yang biasa dikatakan stabilitas marshall sisa.

\section{HASIL DAN PEMBAHASAN}

\section{Karakteristik Material}

a. Agregat

Berikut ini hasil pengujian karakteristik agregat

Tabel 6. Hasil uji karakteristik agregat

\begin{tabular}{|c|c|c|}
\hline No. & Percobaan & Hasil \\
\hline \multirow[t]{5}{*}{1.} & Keausan dengan Mesin Los Angels & \\
\hline & Fraksi A & 7,00 \\
\hline & Fraksi B & 6,6 \\
\hline & Fraksi C & 5,9 \\
\hline & Fraksi D & 4,36 \\
\hline \multirow{4}{*}{2.} & \multirow{4}{*}{ Berat Jenis dan Absorpsi Agregat Kasar } & 2,65 \\
\hline & & 2,68 \\
\hline & & 2,74 \\
\hline & & 1,36 \\
\hline \multirow[t]{3}{*}{3.} & \multirow[t]{3}{*}{ Berat Jenis dan Absorpsi Agregat Halus } & 2,623 \\
\hline & & 2,668 \\
\hline & & 2,748 \\
\hline \multirow[t]{12}{*}{4.} & \multicolumn{2}{|l|}{ Analisa Saringan } \\
\hline & $3 / 4 "$ & 100 \\
\hline & $1 / 2 "$ & 94,79 \\
\hline & $3 / 8 ”$ & 83,23 \\
\hline & No.4 & 65,20 \\
\hline & No.8 & 48,36 \\
\hline & No. 16 & 36,27 \\
\hline & No.30 & 26,41 \\
\hline & No.50 & 27,67 \\
\hline & No.100 & 9,21 \\
\hline & No.200 & 3,89 \\
\hline & PAN & 0,00 \\
\hline 5. & Uji Material Lolos Saringan no. 200 & 6,2 \\
\hline \multirow{2}{*}{6.} & Sand Equivalent & 97,337 \\
\hline & Nilai Setara Pasir & 2,663 \\
\hline 7. & KelekatanAgregat Terhadap Aspal & $>98$ \\
\hline 8. & Pemeriksaan Berat Jenis Filler semen & 3,09 \\
\hline
\end{tabular}

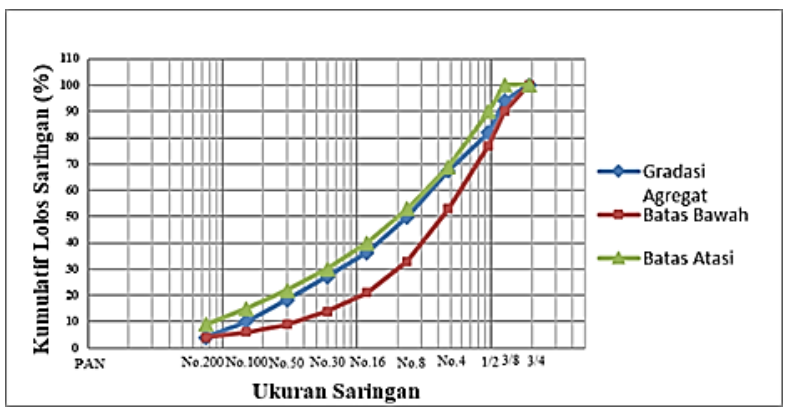

Gambar 2. Grafik analisa saringan agregat
Melalui pemeriksaan material lolos saringan No 200 didapatkan $6,2 \%$ dimana standarnya maksimal $10 \%$. Percobaan ini menunjukkan material tersebut bersih dari lempung maupun lanau.

Melalui Penelitian Nilai Setara Pasir digunakan 2(dua) sampel, sehingga diperoleh hasil 97,336\% merupakan nilai rata-rata Sand Equivalen sedangkan tingkat kadar lumpurnya 2,663\%. Maka untuk tingkat kadar lumpur digunakan spesifikasi minimum $60 \%$ serta pada Sand Equivalen 
Paulus Civil Engineering Journal

E- Jurnal Teknik Sipil UKI-Paulus Makassar

http://ojs.ukipaulus.ac.id/index.php/pcej
Volume 3 No.2, Juni, 2021

ISSN Online 2775-4529

ISSN Print 2775-8613 minimum 5\%, dimana sampel ini mencapai spesifikasi umum Bina Marga 2018. Pemeriksaan kelekatan suatu agregat pada aspal didapatkan telah mencapai $98 \%$ dimana telah memenuhi standar Bina Marga yaitu dengan standar 95\%. Pemeriksaan partikel kepipihan dan kelonjongan Agregat Kasar telah mencapai syarat umum Bina Marga 2018.

\section{b. Aspal}

Aspal minyak penetrasi 60/70ialah aspal yang digunakan pada pengujian ini. Nilai penelitian pemeriksaan penetrasi didapatkan hasil nilai penetrasi $66,7 \mathrm{~mm}$. Dimana minimum 60 "0,1" mm hingga maksimal $70 " 0,1 " \mathrm{~mm}$ merupakan Persyaratan Spesifikasi Umum Bina Marga 2018. Melalui pengujian daktilitas nilai rata-ratanya ialah $150 \mathrm{~cm}$,dimana Persyaratannya yaitu Minimal 100 $\mathrm{cm}$. Berdasrkan pengujian titik lembek aspal diperoleh total nilai $50,2^{\circ} \mathrm{C}$ dimana persyaratannya berkisar antara $48-58^{\circ} \mathrm{C}$. Berdasarkan penelitian Titik Nyala diperoleh hasil keseluruhan $290^{\circ} \mathrm{C}$. Dimana syarat Umum Bina Marga 2018 mensyaratkan Minimal $200^{\circ} \mathrm{C}$. Berdasarkan Berat Jenis dicapai nilai totalnya $1,015 \mathrm{gr} / \mathrm{cc}$. dimana diketahui nilai minimalnya yaitu $1,0 \mathrm{gr} / \mathrm{cc}$. Dengan pengujian penurunan berat aspal dapat diketahui nilainya yaitu $0,434 \%$ dimana persyaratannya Maksimal $0,8 \%$. Pada percobaan penetrasi pada TFOT nilai berat aspal didapatkan nilai totalnya 84,7\%. Dimana persyaratannya Minimal 54\%.

\section{Marshall Konvensional}

Hasil perhitungan Bulk spesific gravity dan Effective spesific gravity untuk campuran Laston Lapis Aus adalah $5,50 \%, 6,00 \%, 6,50 \%, 7,00 \%$, dan $7,60 \%$ dan dapat dilihat pada tabel 7 .

Tabel 7. Bulk Spesific Gravity Effective Spesific Gravity

\begin{tabular}{cccccc}
\hline \multirow{2}{*}{ Nilai } & 5,50 & 6,00 & 6,50 & 7,00 & 7,50 \\
\cline { 2 - 5 } & 2,85 & 2,87 & 2,88 & 2,90 & 2,92 \\
\hline Buk Spesific Gravity Agrerat & 2,90 Effective Spesific Gravity \\
Agrerat & 2,89 & 2,91 & 2,92 & 2,94 & 2,95 \\
\hline
\end{tabular}

Hasil pemeriksaan karakteristik untuk pengujian marshall konvensional dapat dilihat pada tabel 8 :

Tabel 8. Nilai karakteristik marshall konvensional

\begin{tabular}{cccccc}
\hline \multirow{2}{*}{$\begin{array}{c}\text { Kadar Aspal } \\
(\%)\end{array}$} & \multicolumn{5}{c}{ Karakteristik Marshall Konvensional dan Persyaratan } \\
\cline { 2 - 5 } $5,50 \%$ & Stabilitas $(\mathrm{Kg})$ & VIM(\%) & Flow $(\mathrm{mm})$ & VMA (\%) & VFB (\%) \\
\cline { 2 - 5 } $6,00 \%$ & 1535.49 & $3-5 \%$ & $2-4 \mathrm{~mm}$ & Min 15\% & Min 65\% \\
$6,50 \%$ & 1883.37 & 4.56 & 2.90 & 17.08 & 73.30 \\
$7,00 \%$ & 2351.22 & 3.94 & 2,65 & 17.98 & 76.55 \\
$7,50 \%$ & 1913.57 & 3.81 & 2.50 & 18.93 & 79.19 \\
\hline & 1859.38 & 3.43 & 2,70 & 20.01 & 80.94 \\
\hline
\end{tabular}

a. Stabilitas

Pada tabel 7 nilai stabilitas berkisar antara $1535.49 \mathrm{~kg}$ hingga $1859.38 \mathrm{~kg}$, dan telah memenuhi spesifikasi. Grafik keterkaitan antar kadar aspal dan dapatkan Berdasrkan nilai stabilitasnya maka dibawah ini di terbentuk grafik keterkaitan antara stabilitas dan kadar aspal.

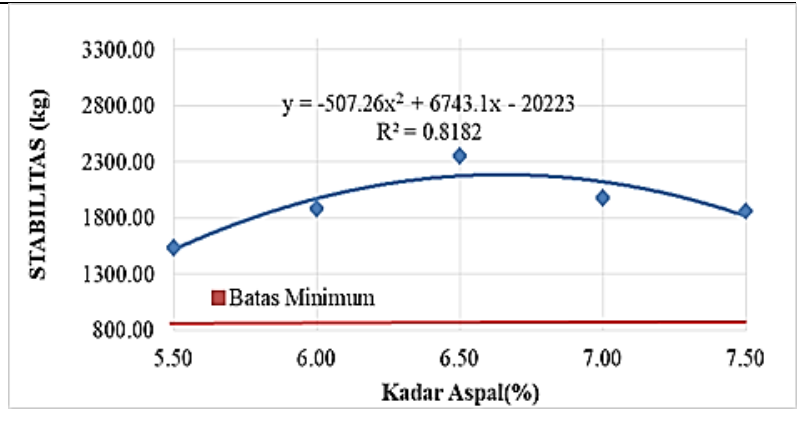

Gambar 3. Grafik hubungan kadar aspal dengan stabilitas

Menurut grafik 3 menunjukkan dalam campuran Laston Lapis Aus kadar aspal yang dipakai sedikit 
maka selimut aspalnya tipis pada permukaan agregat sehingga kaitan antar agregatnya menjadi lemah hingga kekuatan campuran kecil, namun kaitan antar agregatnya akan menjadi lebih kuat ketika kadar aspalnya semakin meningkat (stabilitas campuran besar).

\section{b. Void in Mix}

Perbandingan antara kadar aspal dengan nilai VIM dapat terbentuk grafik seperti gambar dibawah ini:

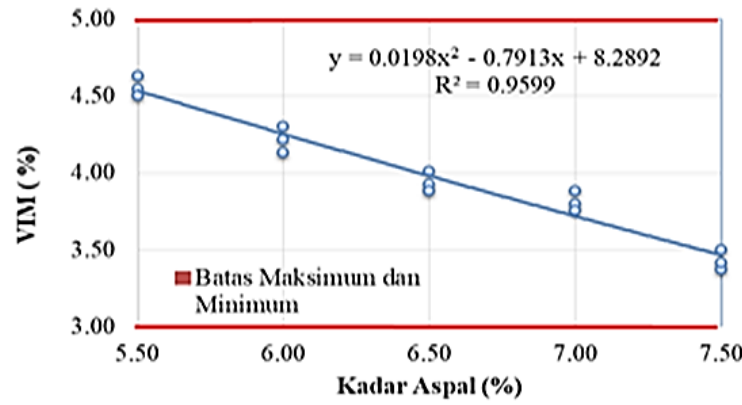

Gambar 4. Grafik hubungan kadar aspal dan VIM

Melalui grafik 4 diatas nilai VIM berkisar 3,43\% $4.56 \%$ dengan menggunakan kadar aspal $5 \%-7 \%$. Hasil Void in Mix tersebut mencapai syarat, pada grafik di atas dilihat dari banyaknya aspal yang dipakai akan mendukung memasukkan rongga antar agregat pada campuran beraspal.

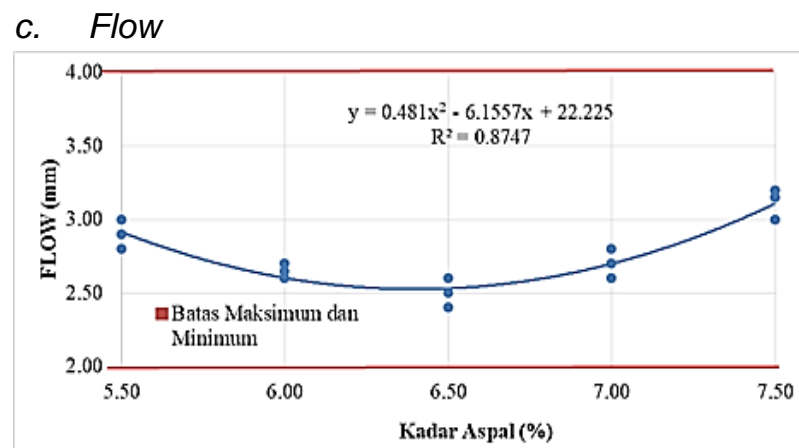

Gambar 5. Grafik hubungan kadar aspal dan flow

Pada grafik 5 diatas memperlihatkan jika nilai flow berkisar antara $290 \mathrm{~mm}$ hingga dengan $3.12 \mathrm{~mm}$ dimana telah memenuhi syarat spesifikasinya dan dapat dilihat pada table 5 .

d. Void in Mineral Aggregate

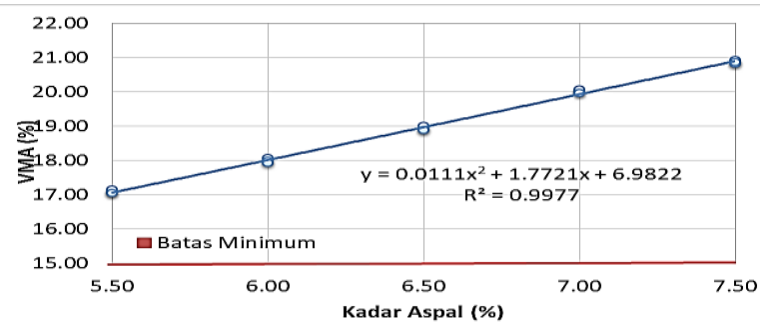

Gambar 6. Grafik hubungan kadar aspal dan VMA

Berdasarkan grafik 6 dapat dilihat bahwa Penggunaan kadar aspal 5,00\%-7,00\%, diperoleh hasil VMA berkisar 17,08 \% - 20,85\%, dan berdasarkan table 5 nilai VMA telah memenuhi spesifikasi. Karena dipengaruhi banyaknya aspal yang digunakan, dikarenakaan kegunaan aspal ialah menyelimuti agregat namun memiliki kegunaan memenuhi rongga diantara agregat dan didalam partikel agregat.

\section{e. $\quad$ Void Filled Bitument}

Pada tabel 5 dan grafik 7 menunjukkan hasil analisis Berdasarkan analisis VFB, menunjukkan nilainya berkisar $73,30 \%$ hingga $83,57 \%$ dan telah memenuhi spesifikasi.

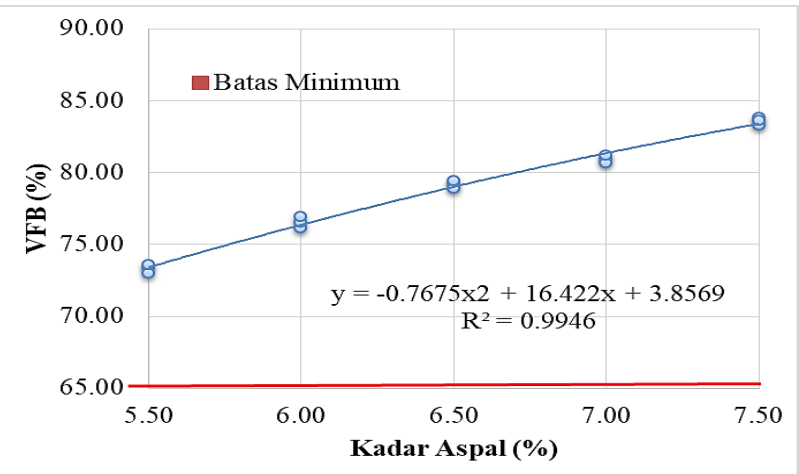

Gambar 7. Hubungan kadar aspal dan VFB

\section{Penentuan Kadar Aspal Optimum}

Kadar aspal praktis yang sangat rentang kadar aspal yaitu sebesar 5,50-7,5\% dan sudah memenuhi syarat untuk campuran Laston Lapis Aus. Sehingga pada campuran Laston Lapis Aus yang mempunyai nilai vim terkecil yaitu $7,5 \%$ dikarenakan Laston Lapis Aus adalah lapis lapis binder yang mampu melindungi lapisan dibawahnya.

\section{Stabilitas Marshall Sisa}

Untuk penentuan kadar aspal optimum yaitu kadar aspal $7,5 \%$ kemudian direndam selama kurang 
lebih 24 jam pada suhu $\pm 60^{\circ} \mathrm{C}$. maka proses

kadar aspal tertinggi. selanjutnya ialah membuat benda uji berdasarkan

Tabel 9. Stabilitas marshall sisa

\begin{tabular}{cccc}
\hline \multirow{2}{*}{ Kadar Aspal (\%) } & \multicolumn{2}{c}{ Nilai Stabilitas } & \multirow{2}{*}{ SMS } \\
\cline { 2 - 3 } & Konvensional & Immersion & 99,35 \\
7,50 & 1847,39 & 1835,39 & 99,35 \\
7,50 & 1859,39 & 1847,39 & 99,36 \\
\hline 7,50 & 1871,38 & 1859,38 & 99,35 \\
\hline Rata-rata & 1859,38 & 1847,39 & \\
\hline
\end{tabular}

Untuk mendapatkan nilai stabilitas marshall sisa pada campuran, berikut ini merupakan hasil uji dari stabilitas marshall sisa campuran, seperti dilihat pada tabel 9 .

Nilai stabilitas marshall sisa didapatkan berdasarkan selisih antar stabilitas dari benda uji Marshall setelah dilakukan perendaman pada wadah berisi air selama 24 jam pada temperature $60^{\circ} \mathrm{C}$ terhadap stabilitas contoh uji Marshall melalui perendaman 0,5 jam (30 menit) pada suhu $60^{\circ} \mathrm{C}$.

Melalui pengujian Marshall Immersion didapatkan stabilitas marshall sisa ialah $99,35 \%$ dengan kadar aspal $7,50 \%$, dimana nilai minimumnya yaitu $90 \%$, dimana sudah mencapai spesifikasi Bina Marga tahun 2018 minimal 90(\%).

\section{KESIMPULAN}

Pemanfaatan Batu Gunung Sopai Kabupaten Toraja Utara untuk campuran Laston Lapis Aus, karakteristik aspal dan berat jenis filler memenuhi persyaratan berdasarkan spesifikasi umum Bina Marga 2018.

Rancanagan Komposisi pada campuran Laston Lapis Aus yang digunakan adalah kadar aspal yang memiliki nilai optimum yaitu $7,5 \%$ berdasarkan nilai vim terendah dengan memperhatikan jumlah agregat kasar, agregat halus dan berat jenis filler.

Berdasarkan hasil penelitian Karakteristik campuran Laston Lapis Aus di Laboratorium Jalan dan Aspal Universitas Kristen Indonesia Paulus melalui pengujian Marshall Konvensional diperoleh karakteristik campuran beraspal flow, VMA, VIM, VFB dan stabilitas telah memenuhi spesifikasi umum Bina Marga 2018.

\section{DAFTAR PUSTAKA}

[1] S Sukirman, 2003, Pekerjaan Lentur Jalan Raya, Edisi Kedua. Bandung: Nova.

[2] Direktorat Jendral Bina Marga, 2018, Spesifikasi Umum Bina Marga 2018 untuk Pekerjaan Konstruksi jalan dan jembatan. Jakarta Indonesia: Kementrian Pekerjaan Umum dan Perumahan Rakyat.

[3] Laboratorium Aspal, 2018, Panduan Praktikum Jalan \& Aspal Teknik Sipil. Makassar: UKI-Paulus.

[4] Direktorat Jendral Bina Marga, 2018, Perkerasan Aspal Devisi 6. Jakarta: Kementrian Pekerjaan Umum dan Perumahan Rakyat.

[5] Departemen Pekerjaan Umum , 2018, Ketentuan Sifat Sifat Campuran Beton Aspal. Jakarta: Kementrian Pekerjaan Umum dan Perumahan Rakyat.

[6] Laboratorium Jalan dan Aspal, 2018, Metode Pengujian Agregat: Badan Penelitian dan Pengembangan Departemen Pekerjaan Umum.

[7] Fani, A L, 2009, "Pemanfaatan Agregat Sungai Wanggar Kabupaten Nabire Sebagai Bahan Campuran AC-WC dan AC-BC," Paulus Civ. Eng. J., Volume. 1, Nomor 2. HIm. 28-36.

[8] Palimbunga, G. P., 2020, "Penggunaan Agregat Sungai Batu Tiakka' Pada Campuran AC-BC," Paulus Civ. Eng. J., Volume. 2, Nomor 2. HIm. 112-118.

[9] Yudi, A., 2020, "Karakteristik Campuran AC-WC dan AC-BC Menggunakan Bahan Tambah Serat ljuk," Paulus Civ. Eng. J., Volume. 1, Nomor 1. HIm. 1-9. 